\title{
Beyond a Fad: Why Video Games Should Be Part of 21st Century Libraries
}

By Kym Buchanan and Angela M. Vanden Elzen

\section{Abstract}

We believe video games have a place in libraries. We start by describing two provocative video games. Next, we offer a framework for the general mission of libraries, including access, motivation, and guidance. As a medium, video games have some distinguishing traits: they are visual, interactive, and based on simulations. We explain how these traits require and reward some traditional and new literacies. Furthermore, people play video games for at least three reasons: immersion, challenge, and connection. Finally, we offer guidelines and examples for how librarians can integrate video games into library collections and programming.

\section{Introduction}

Change is inevitable. Growth is intentional. -Glenda Cloud

We live and work with change. New and evolving media and technology affect our jobs, politics, recreations, relationships, children, and more. We face an endless flood of gadgets and wizardry: iPads, smartphones, Facebook, Twitter, e-books, Wikipedia, video games, etc. This flood can be confusing and intimidating. Libraries and librarians can play vital roles in helping patrons live and work with change.

In this article, we'll explore one area of evolving media and tech: video games. We believe video games have a place in libraries, and thus librarians should try to understand the nature of video games, especially why people play video games. Games illustrate powerful phenomena in media and tech, including interactivity and immersion.

Now is a good time for librarians to explore video games. Recently, the United States Supreme Court considered arguments about the nature and possible effects of video games. The Court applied First Amendment protection to video games: "Like protected books, plays, and movies, they communicate ideas through familiar literary devices and features distinctive to the medium" (Brown v. EMA, 2011). The Court prevented California from restricting the sale of video games to minors. Their decision effectively halted similar efforts in other states. However, Justices writing both in the majority and minority acknowledged that the nature and possible effects of a new medium like video games can be poorly understood. For example, Justice Scalia recounted our nation's past confusion and alarm about the possible harm to minors caused by penny dreadfuls (lurid novels), movies, and comic books (Brown v. EMA, 2011). As a society, we live and work with phenomena like interactivity and immersion, so we should explore and discuss the possible advantages and risks, especially the possible harms to minors. Libraries and librarians can and should be part of this exploration and discussion.

Fortunately, librarians don't need to be avid "gamers" to learn about video games and to appreciate the place video games could have in libraries. However, librarians may need to learn more about the appeal of video games. There is an endless variety of new games and kinds of games, and this flood isn't likely to ebb. In this article we won't try to catalog the flood. Rather, we hope to equip librarians with a better understanding of the nature and appeal of video games. What are the distinctive features of the medium? How do games communicate ideas?

First, we'll describe two examples of provocative video games. Second, we'll describe the possible roles of libraries during changing times. Third, we'll explore why people play video games. Fourth, we'll explore how video games can be part of libraries, with specific suggestions. 


\section{Examples}

There are many video games worth playing and discussing. We've chosen two examples that vividly illustrate the potential of video games to intrigue and provoke: September 12th and Beyond Good \& Evil. These examples demonstrate how games can honor the spirit of the First Amendment, not just enjoy its protection.

\section{September $12^{\text {th }}$}

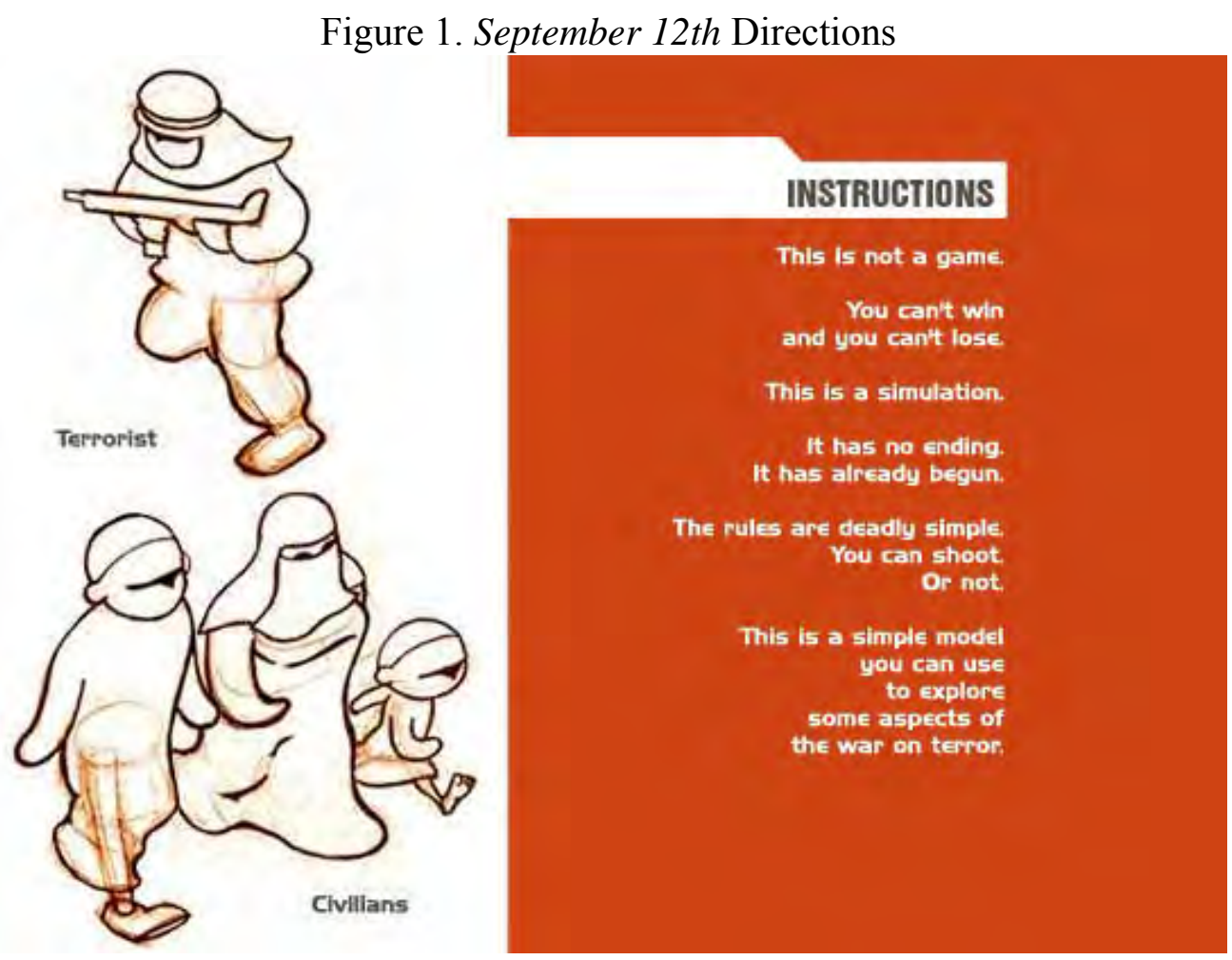

Following the terrorist attacks on September 11, 2001, the United States and the world struggled to make sense of our situation in the "post-9/11" era. We tried to understand who had attacked the US and why, and what we could and should do in response. A team of game designers wanted to influence the discussion. September 12th (Newsgaming.com) was published in 2003, as a free, browser-based game. At this time, this short game is still online so we encourage readers to play it (see:

http://www.newsgaming.com/newsgames.htm).

September 12th demonstrates how visual communication, interactivity, and simulation can be combined to encode a provocative message. The game is based on a simple simulation of a nameless Middle Eastern city, and the visual style is cartoonish but not frivolous. The city is crowded with men, women, children, and dogs walking around. Most of the people are civilians dressed in blue, traditional clothing. Some adults are terrorists: they carry assault rifles and wear distinctive white keffiyeh (cloth headdresses). The game offers simple directions (Figure 1).

The player controls a crosshair which can be used to launch missiles. There is a short flight time between launching a missile and its impact, and the explosion has a large radius. It's difficult to hit a terrorist without accidentally damaging buildings or killing civilian bystanders. Other civilians come to weep over the corpses and then these mourners transform into new terrorists. This transformation is visually striking and accompanied by a distinctive sound effect. The more explosively the player pursues terrorists, the more the surviving civilians are inspired to become terrorists (Figure 2, Figure 3). 


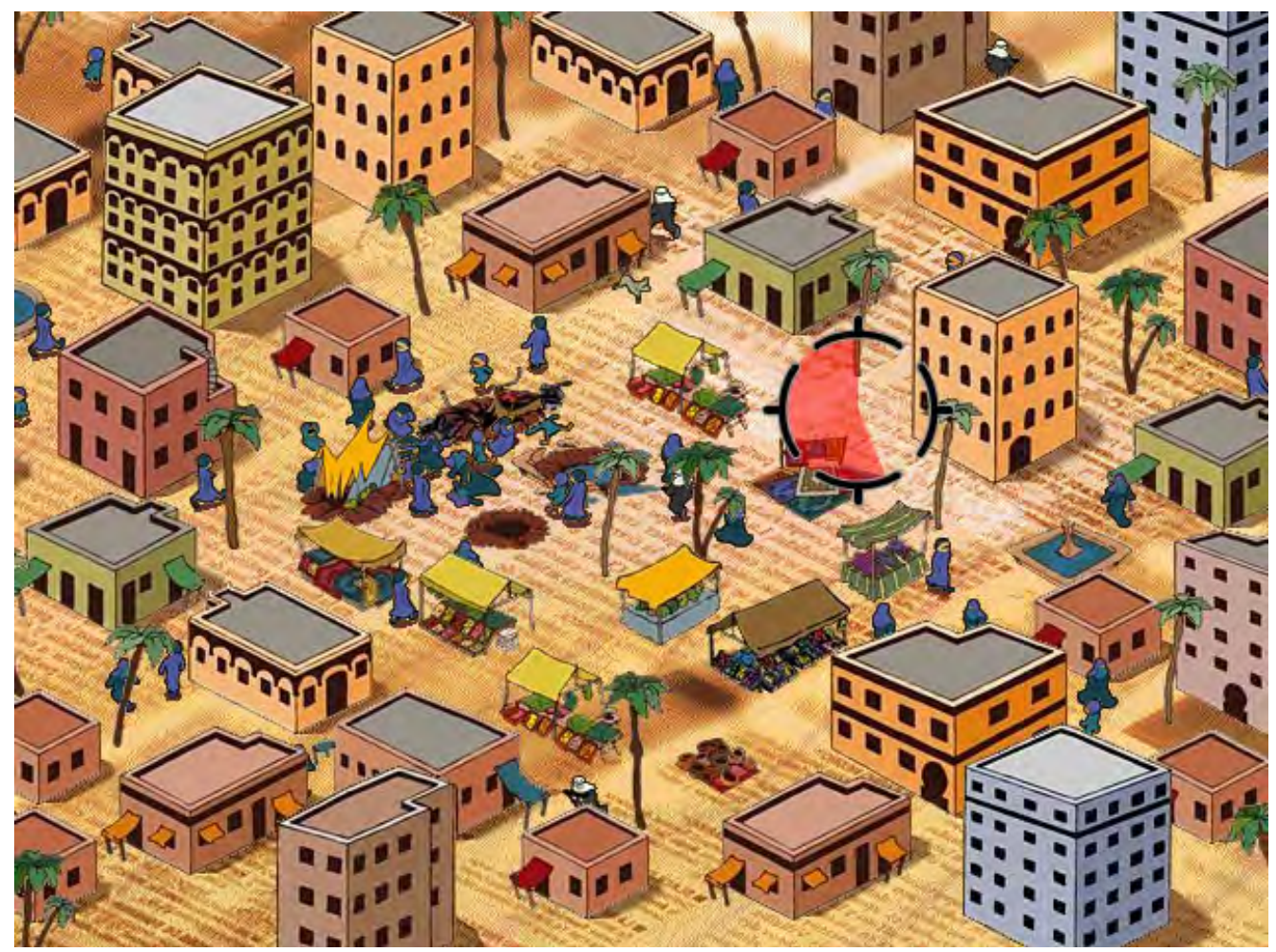

Figure 3. September 12th close-up: a mourner becomes a terrorist
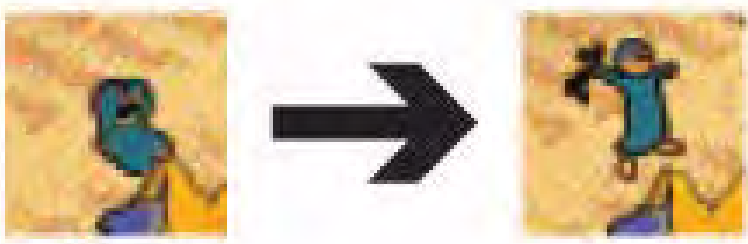

Targeting terrorists in an urban setting is a messy problem: missiles can inflict collateral damage, sending in soldiers puts them in harm's way, terrorists can hide among civilians, etc. September 12th is a provocative editorial on the problem. Players may disagree with the game's message, but for our purposes the validity of the message isn't important. What's distinctive about the game is that it is a game. It's interactive: the player will almost inevitably fire at least one missile, if only to see what happens. The player may experience the game's message with greater impact because the player's choices have visible consequences. A well-written newspaper editorial or a striking photograph can impact an audience, yet interactive media like games frame a different kind of relationship between author and reader. Also, consider the audiences reached by more traditional editorial media versus the audiences that may play a free video game. Some players may not invest time and energy in watching or reading the news, but they may play and discuss September 12th. In summary, September 12th is based on a simple simulation with assumptions about some roots of terrorism. When players interact with the game, they can decode its messages through its striking visual communication. The game tries to influence the player's thinking: it tries to affect the player's perspective on "some aspects of the war on terror" (Newsgaming.com). 


\section{Beyond Good \& Evil}

Figure 4. Beyond Good \& Evil box cover art

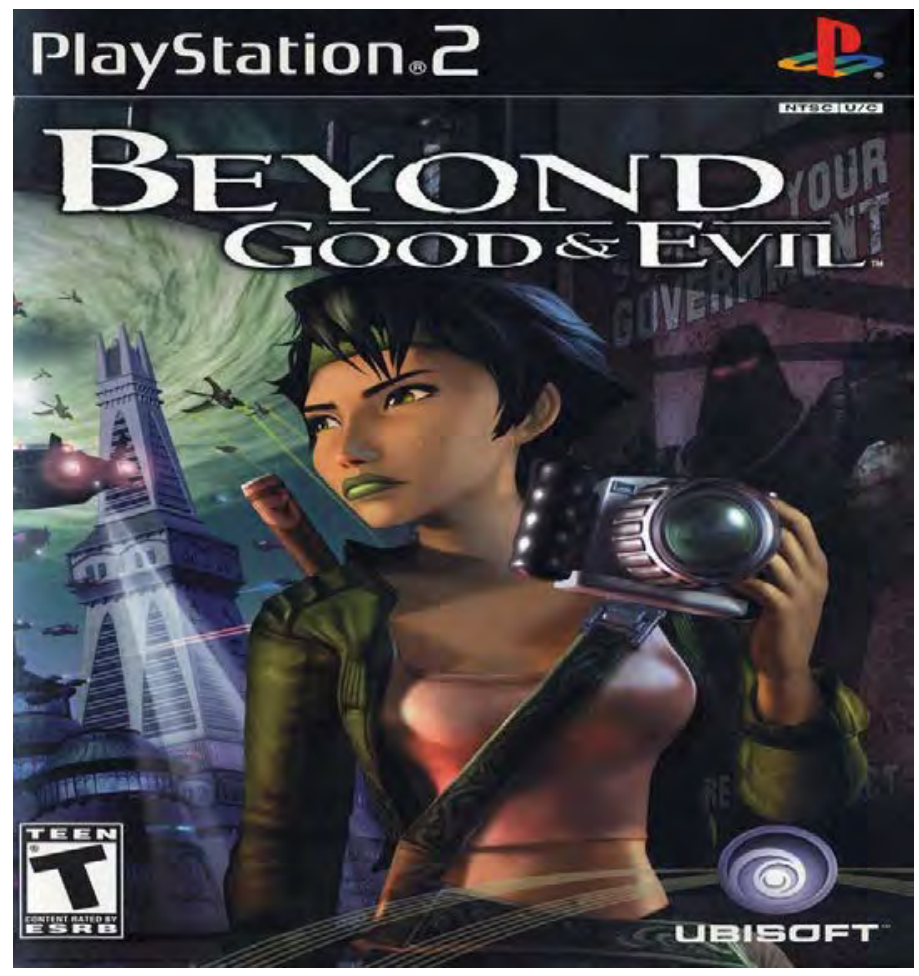

Figure 5. Beyond Good \& Evil gameplay

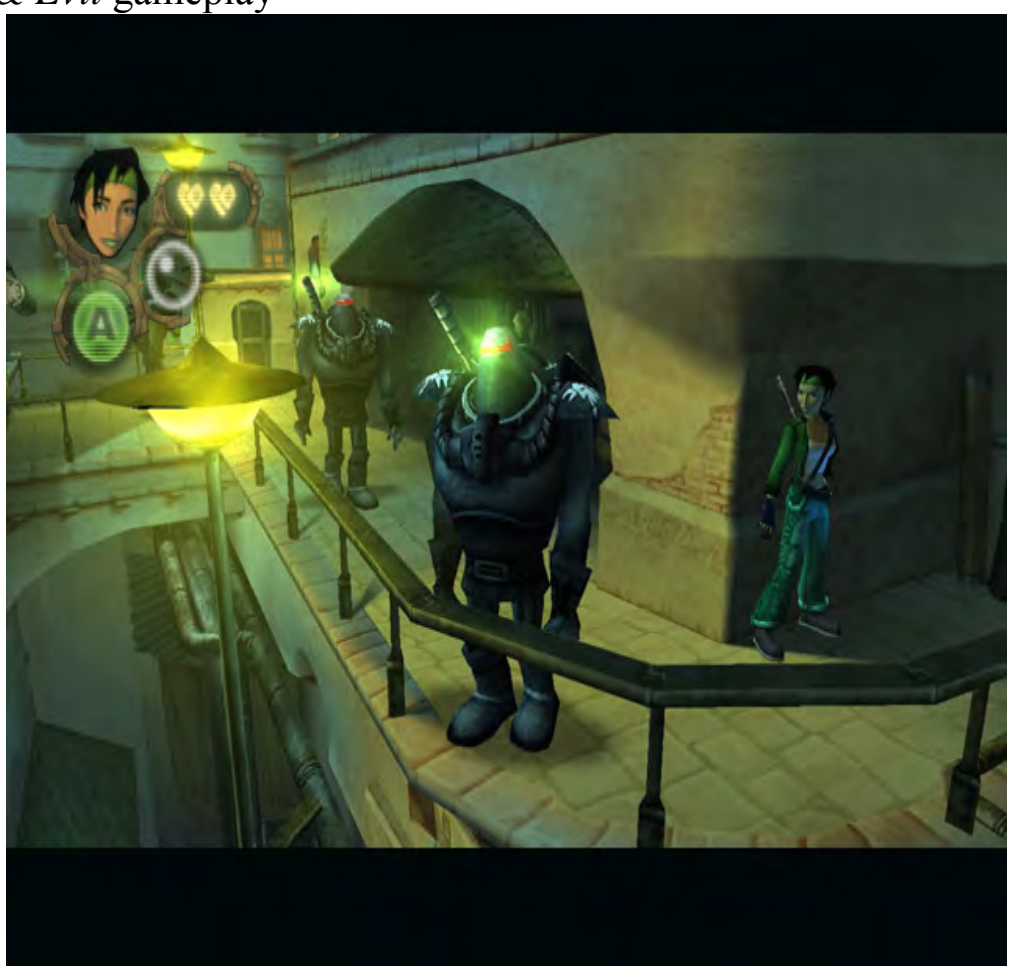

Beyond Good \& Evil (BG\&E) is another game that tries to provoke thinking about post-9/11 issues, including patriotism, paranoia, and the role of dissent in a democracy (e.g., challenging government decisions). Beyond Good \& Evil (Ubisoft) was first published in 2003 for several video game systems. At this time, an updated version can be bought online for Xbox 360 and PlayStation 3. 
$B G \& E$ is a far more sophisticated video game than September 12th and requires many hours to finish. (The game saves the player's progress so it can be played over time.) $B G \& E$ is based on a simulation of an imaginary planet called Hillys. The setting is a mix of science fiction and fantasy, with alien wildlife and sentient beings. An off-world army of alien DomZ is invading but Hillys is allegedly defended by General Kehck and the Alpha Sections. Kehck broadcasts reassuring messages to the citizens of Hillys. His messages are bombastic, ultra-nationalist propaganda - perhaps a deliberate parody of some real rhetoric of the post9/11 era.

The player takes on the identity of Jade, a female, Hispanic photojournalist (Figure 4). Jade is recruited by an underground resistance movement called the IRIS Network. IRIS suspects the government is corrupt and lying about the war. Jade sneaks into government facilities and takes revealing pictures. As Jade's stories are published, the public starts to question the government. For example, protestors start appearing in the streets. Eventually, Jade and her allies collect enough evidence to incite a full revolt: the invaders and collaborators are unmasked and defeated.

$B G \& E$ has a stylized visual aesthetic (Figure 5). (Creator Michel Ancel was inspired by Miyazaki films (Bertz, 2011).) BG\&E simulates a "living world" in which Jade can interact with a variety of creatures and obstacles in a variety of ways (e.g., sneaking, taking pictures, fighting). Some of the choices and consequences are especially provocative. For example, Jade provides foster care to war orphans. The player can interact with the orphans and experience an unusual perspective on war. As another example, Jade has a side job taking pictures of the native flora and fauna. A conservation organization is worried about the possible extinction of some native species during the war and thus pays Jade for creating a photographic record. At different times, $B G \& E$ is tense, funny, scary, sad, or wily. It offers subtle and not-so-subtle allegory. For example, Jade repeatedly visits a bar to meet her contacts in the IRIS Network. The song playing in the bar includes the refrain "Propaganda!"

In summary, $B G \& E$ invites players to explore a visually-striking world at war. When players interact with the simulation, they take on Jade's identity and roles. These roles include concerned citizen, investigative reporter, and foster parent. $B G \& E$ uses allegory to express messages about civil disobedience and the watchdog role of journalists.

\section{Changing Times}

September 12th and Beyond Good \& Evil are two examples of the rich, provocative, and evolving medium of video games. The short history of video games is a story of change: the technology and artistry have grown exponentially in a short time. In the early 1980s most video games were simple, two-dimensional, singlescreen experiences like Pac-Man or Donkey Kong. Gameplay involved sharp eye-hand coordination, fast reflexes, and simple tactics. The stories in video games were equally simple. Today, many games offer sophisticated, three-dimensional living worlds, like Hillys in Beyond Good \& Evil. Gameplay can involve analyzing systems, managing multiple resources, and applying complex strategies. The story in a modern video game can rival a novel in depth and length. Games will continue to evolve as the technology and artistry evolve.

Games are part of the larger flood of evolving media and tech. As librarians consider how to respond to change, it may help to revisit the mission of libraries. It may also help to consider the fundamental nature of games. 


\section{Access, Motivation, and Guidance}

Changes in media and tech can challenges the relevance of institutions like libraries. An institution remains relevant when it remains an effective approach to important problems. Recently, many public libraries have faced budget cuts or even closure: libraries are under pressure to demonstrate their value to society (Karas, 2011). We believe the continued relevance of libraries depends how librarians define their mission and how libraries evolve to achieve that mission. We identify three important services libraries can provide: access, motivation, and guidance.

Access is the most visible and celebrated service. Libraries that are open to the public are especially remarkable since they make media and tech available to everyone. For example, the World Wide Web is accessible to more people because public libraries offer free, networked computers. Access can even be an equalizing force. National Council of Teachers of English President Siu-Runyan (2011) argues that access to "a good library can offset the effects of poverty on reading achievement" (p. 29).

Motivation is often more subtle. Most librarians can only coax, not command. They try to inspire patrons to visit libraries, browse the selection, and check out materials. For example, librarians may hang up posters of celebrities promoting reading. Librarians' attempts to motivate are most admirable when they spring from an infectious love of discovery, enjoyment, and learning.

Guidance can be even more subtle. Guidance is not control or censorship. Indeed, many librarians oppose censorship: "ALA has long championed the freedom of the press and the freedom to read" (American Library Association, n.d.). Rather, guidance is connecting with the needs and interests of patrons, and making suggestions to help patrons find answers and enjoyment. Sometimes librarians advocate for the opinions of others, like setting up a display of New York Times best sellers or Newberry and Caldecott Medal winners. Sometimes librarians try to bridge from patrons' existing interests, like recommending books related to current events. Guidance is different than the direct teaching in a school in which teachers assign reading and assess comprehension. Guidance is also different from retail sales in which profit is a factor in assisting customers.

Recently, libraries have continued to provide access, motivation, and guidance while adapting to changes like CD-ROMs and the Web. Libraries can continue to evolve by including video games.

\section{Visual Interactive Simulations}

Video games are a new medium with new affordances and constraints. The possible choices when designing a game demarcate how a designer can encode a message as a game. These possibilities also demarcate how a player decodes and experiences the message through playing the game. It's not unusual for new media to alter communication. For example, movies use a lexicon of visual communication. Since video games have unusual affordances and constraints, we can ask whether video games represent a new literacy.

Video games do introduce a new literacy because messages are encoded and decoded in new ways. However, some essential skills are unchanged for designers and players--authors and readers. These skills include audience consideration, creating dramatic tension, interpreting metaphors, and extrapolating an author's intent. We'll explore how libraries can help patrons develop these skills, by first deconstructing the medium. As a medium, video games have several distinguishing traits. A video game is a visual experience, it's interactive, and it's based on a simulation.

Almost all video games center on a strong visual experience. Game designers often draw on design choices in other visual media like movies and comic books. Some designers use photorealistic graphics (e.g., 
Bioshock) while others use stylized or even abstract representations (e.g., Viewtiful Joe, Echochrome). There are a few distinct exceptions of games that aren't centered on a visual experience, including text-only adventure games like Multi-User Dungeons (MUDs).

The visual experience of most video games shapes the essential and advanced literacies. As one essential literacy, many video games use icons to communicate. For example, in Beyond Good \& Evil Jade's health is represented by a series of filled hearts (Figure 5). When most of the hearts are empty, Jade's health is poor and further injury will lead to death. A player needs to develop essential literacies in order to play a game. Otherwise, the experience will seem random ("Why did my character die?"). The advanced literacies are more complex and include skills like recognizing satire and interpreting allegory.

The advanced literacies are connected to interactivity. The highly interactive nature of games gives the player far greater initiative and influence over how the experience unfolds. The designer may offer very overt messages through the setting, characters, and plot. More subtle messages can be found and interpreted through playing the game. Critics often tout good "gameplay" as the most important ingredient in a good video game. Gameplay mainly refers to the nature of the interactivity: the kinds of choices, the consequences of choices, and the feedback that teaches the player the relationship between a choice and consequence. The most sophisticated video games are often marketed and praised for the variety of choices and consequences they offer. For example, in best-selling series like Grand Theft Auto and Fallout, the games offer extensive, meaningful choices with colorful, divergent consequences.

However, while the experience may unfold very differently for different players, it's still ultimately constrained by the designer. The sophisticated worlds of today's games offer a variety of choices and consequences, but this variety is still a relatively small subset of real and imaginary possibilities. We can view video games as one area on a larger continuum of interactivity that also includes hypertext and interactive fiction.

With hypertext, an author can create a website with extensive internal cross-linking. This gives the reader the freedom to move around and through the text in non-linear ways but all the possible moves are still defined by the author. As Aarseth (1997) says, "The reader's freedom ... is a promise easily retracted and wholly dependent on the hypertext system in question" (p. 77).

Interactive fiction is another area of the continuum of interactivity. The Choose Your Own Adventure (CYOA) series of young adult novels is a good example of interactive fiction. A CYOA novel consists of indexed possible story segments. At the end of each segment, the reader is given two or more choices. Each choice leads to a different segment, continuing the story in different directions. A CYOA novel can be reread while making different choices, leading to a different story. Such novels of interactive fiction are sometimes called "gamebooks." Compared to a CYOA novel or a cross-linked website, the interactivity in a video game can be far more sophisticated. But no matter how big the sandbox, the boundaries and the possible choices are still set by the game designer (Squire, 2006). So some traditional literacies are still salient, like interpreting an author's intent.

The third distinguishing trait of video games is simulation. The choices and consequences in a game form a microcosm: a limited model of a real or imaginary reality. One video game may be a simulation of a battlefield, with choices and consequences around tactical planning, firing guns, and invading territory (e.g., Halo). Another game may be a simulation of a suburban family, with choices and consequences around eating, sleeping, and going to work (e.g., The Sims). Building a simulation may require literacies in mathematics and systems thinking. However, a player often doesn't need those specialized literacies to develop a functional understanding of the underlying simulation in a video game. Instead, the player can 
develop a mental model of the simulation through playing the game, developing an understanding of the choices and consequences through trial and error. Yet the player may not appreciate the nuances of the simulation or how they can apply their understanding in other contexts. For example, consider how September 12th simulates the transformation of mourners into terrorists: it's immediate, fast, and predictable. This speeds up the game at the expense of realism. A player may not appreciate the issues and pacing when real people's grief and outrage become resistance and violence.

Recognizing nuances while interacting with a simulation is a new literacy. However, recognizing an author's choices and assumptions is a traditional form of critical literacy. This includes recognizing artistic license. For example, in a movie or novel, the author may use assumptions that create a more historically-accurate story or a more dramatic and faster-paced story. This parallels the decision to make the transformation of mourners faster or more realistic. Without critical literacy, a player may not appreciate how a simulation, movie, or novel simplifies some aspects of the setting, characters, or plot. Players need a mix of new literacies and traditional critical literacy to appreciate such nuances. Critical literacy is also useful in recognizing the overt and subtle assumptions or biases of designers and readers/players (including ourselves). For example, while exploring the multiplayer simulation of Second Life, Werts (2008a) notes that "nearly everyone online is ... fabulously gorgeous, has spectacular clothing, sports killer hair, and is-of course-thin." This fantasy fulfillment may be fun, but without critical literacy players in Second Life may unconsciously perpetuate and internalize unrealistic beauty norms.

In summary, video games have distinguishing traits as a medium: they are visual, interactive, and based on simulations. These traits require and reward some traditional and new literacies. However, it's possible to understand these traits and still miss the essential nature of video games: why they can be very appealing.

\section{Why We Play}

Video games are appealing to many people. There are many explanations for why people play video games. We're going to explore some of the most compelling explanations. We believe there are at least three reasons people play video games: immersion, challenge, and connection.

\section{Immersion}

Immersion is a very appealing experience and it's not unique to video games. "Immersion is the semivoluntary experience of being transported into a new context - a narrower or alternate context - for an extended duration" (Buchanan, 2006). Some people have never been immersed in a video game. But most people have experienced immersion in a book or movie. We crave immersion for reasons like stimulation, escapism, and self-discovery. Immersion is semi-voluntary. While we may choose to become immersed in experiences, we can't fully control the experiences. For example, people may choose to watch scary movies or play scary video games, but they can't fully control how scared they get.

Video games allow players to be and do exciting, scary, and wonderful things. Players can become immersed in experiences beyond their normal lives. Video games can be more personal and immersive than other media and tech because the players have a more active role. In September 12th, the player doesn't merely watch a missile attack: the player fires the missile. Once immersed in the designed experience of a video game, a player is more sensitive to the affordances and constraints of the simulated domain (e.g., "the war on terror"). The player experiences these affordances and constraints with palpable immediacy: the nuances of choices and consequences are instantly and closely felt. In September 12th there is a palpable immediacy to the consequences of the choice to shoot.

The immersion in a sophisticated game like Beyond Good \& Evil can be much deeper if a player is receptive to the identity being offered. A player can start seeing the world and challenges through the character's eyes. Then the palpable immediacy of moment-to-moment choices and consequences contributes to a continuous experience: an overarching identity that's a composite of character and a player. The designers of $B G \& E$ 
created the setting, dialog, and choices for Jade, but the player co-constructs the character by how he plays the game. For example, one player may co-construct a Jade who is stealthy and evasive while another player's Jade is confrontational and violent. Different players will take away different impressions of the game based on what they bring to the game, how they play the game, how immersed they become in the character and world, and how they later process on their choices and consequences.

The palpable immediacy of immersion and the co-construction of identity support what Gee (2003) calls "embodied experience" (p. 108). After playing in a video game an individual may have a deeper understanding of the relevant domain and roles. The player can learn about choices and consequences through interaction and co-construction, not just passive reception. Gee builds on the ideas of Barthes and others. Barthes (1968/1977) offers a compelling perspective on how a reader co-constructs the messages of a text from the text itself and from what the reader brings: "a text's unity lies not in its origin but in its destination... the birth of the reader must be at the cost of the death of the Author" (p. 189). Barthes' $(1971 / 1977)$ perspective is a powerful tool for thinking about video games as a co-constructed experience: "the Text is experienced only in an activity of production..." (p. 167). This co-construction is more vivid in video games than in most other media.

In short, interactivity and immersion can increase the intensity of an experience. This positions players to be more affected by a video game. Players seek this influence: they crave the mental and emotional stimulation of immersion.

\section{Challenge}

Many media and tech offer mental and emotional stimulation. Video games are unusual because they offer a particular kind of stimulation: challenge. Some other media offer some challenge, like the "whodunit?" of a mystery novel or the non-linear scenes of movies like Memento. But these other media don't test us like video games. We can keep turning the pages of a mystery novel even if we're missing essential clues, but in most video games our progress is contingent on facing and overcoming uncompromising challenges. The challenge of these tests is an inherent part of the games' appeal.

People seek challenge for some of the reasons they seek immersion: stimulation, escapism, and selfdiscovery. Many people enjoy challenge, especially when the challenge closely matches their abilities: neither too easy nor too hard. Gee (2003), Johnson (2006), and others have emphasized how good video games offer this kind of optimal challenge. Csikszentmihalyi (1990) is a visionary on the labors and pleasures of optimal challenge in any activity. He describes a desirable state of being called "flow":

The best moments usually occur when a person's body or mind is stretched to its limits in a voluntary effort to accomplish something difficult and worthwhile. ... ...flow - the state in which people are so involved in an activity that nothing else seems to matter; the experience itself is so enjoyable that people will do it even at great cost, for the sheer sake of doing it. (p. 3-4)

In describing the enjoyable challenge of media and tech like video games, Papert (2002) uses the phrase "hard fun." Video games are one of many possible activities for finding the hard fun of flow. Some video games are particularly effective for flow because they have one or more of the following features. They adjust to the player so the difficulty is often right at the edge of the player's abilities. They offer open-ended problems or worlds so the player can apply solutions based on their particular skills or style. They are selfpaced so the player can progress at their own speed. Above all, they offer clear, immediate feedback, contributing to a progressive sense of accomplishment. Clear, immediate feedback is essential to flow: the palpable immediacy of the reactive nuances creates a tight feedback loop of choices and consequences. Feedback helps players learn how to succeed in a video game. The video game teaches players how to effectively perceive and act in response to challenges in the simulation. In at least some cases players can 
apply this learning to similar contexts beyond the game. The learning is portable. Educators call this phenomenon "transfer." Transfer depends on many factors, including whether the simulation is sufficiently authentic: the affordances and constraints in the simulation must be sufficiently similar to those in the real domain (Aldrich, 2004; Galarneau, 2005). By learning to overcome challenges in the simulation, players learn knowledge, skills, and dispositions they can transfer beyond the game.

Transfer is an ultimate goal of a formal schooling. Teachers try to create activities that are sufficiently authentic to promote transfer. Transfer is what matters, not the activity. Honebein (1996) explains:

Many people misunderstand the true nature of authentic activities. People ask, "How are simulations 'authentic' when by their very nature they are not authentic at all? They're still a simulation." The aim of authentic activity is not just to simulate or replicate the physical environment, calling it "authentic." Rather, the aim is to design an environment in which learners use their minds and bodies as they would if they were practitioners in a domain. It is the purpose of the learning environment, whether it be simulation, actual practice, or independent study, to stimulate learners so that their thinking is related to actual practice.... (p. 20)

Johnson (2006) also argues that the transfer of thinking ability is the chief lasting benefit of immersive media and tech. Whether we're watching a television show with a sophisticated plot or playing a video game with sophisticated challenges, the content isn't as important as the advanced problem-perceiving and problemsolving skills we can take away. Shaffer (2006) makes a similar argument when he describes the interconnected nature of skills, knowledge, identities, values, and epistemology. He deconstructs some games and game-like simulations that foster effective problem-perceiving and problem-solving in authentic domains.

An inherent part of the potential power of games for learning is their appeal. Young people may be more motivated to engage and persist with video games than with other educational media or activities. This leads education experts like Gee (2003) to ask, "Wouldn't it be great if kids were willing to put in this much time on task on such challenging material in school and enjoy it so much?" Games are appealing because of challenge (not in spite of it), and because games change the stakes of success and failure. Inside the "magic circle" of a game, the stakes are lower or different (Rodriguez, 2006; Salen \& Zimmerman, 2004). Thus, players are more willing to engage in "Trying Trio" behaviors: admit ignorance, take risks, and make mistakes (Buchanan \& Cook, In Press). These behaviors are powerful catalysts for learning.

Unfortunately, video games' appeal leads to some possible harms. Most video games require continuous attention, repetitive manipulation of the controls, and no other physical activity. However, our eyes and hands need regular breaks to avoid harms like repetitive stress injury and our bodies need regular exercise to stay healthy. We also need to balance playing games with other activities and relationships. Thus, excessive play can be harmful. However, some research suggests caution before assuming that young people who play video games are less physically active than others (Rideout, Roberts, \& Foehr, 2005). Also, some video games promote physical activity (e.g., Nintendo Wii, Xbox 360 Kinect).

Another possible harm arises when minors are attracted to games with potentially inappropriate content (e.g., graphic violence). Games designed and marketed to adults may contain content that younger players shouldn't play without adult supervision or at all. The Supreme Court and others have compared this possible harm to that of any media, especially if minors play without critical literacy (Brown v. EMA, 2011). In short, challenge can be pleasurable, especially when the difficulty is just right. Interacting with a simulation can provide the optimal challenge of flow. If the simulation is sufficiently authentic, players can learn transferrable knowledge, skills, and dispositions. Games have some possible harms so guidance is important. 


\section{Connection}

A third reason people play video games is to make connections. We want to connect with ourselves, with people close to us, and as a society.

We want to connect with ourselves. Immersion and challenge support self-discovery. When games test our strengths and limits, we learn about ourselves and earn pride. We can learn more about ourselves in games with rich characters and stories. In such games, we can learn about our real and ideal identities: what roles we find apt and desirable and what values we hold highest. Many kinds of media can tell stories that help us explore our real and ideal identities. The interactivity of games makes them especially powerful for this kind of connection. A good game is usually a source of powerful story elements: choices and experiences that cause us to think and feel, and from which we can tell stories. We can tell stories to ourselves as we're playing and we can tell stories to ourselves afterwards. As we make choices and reflect on them, and discuss our choices with others, we can rehearse and review our identities and values. For example, in Beyond Good \& Evil we can discover that we enjoy the role of investigative journalist and that we value speaking truth to power. As Gee (2005) reminds us, it can be immensely satisfying and empowering to tell coherent and revealing stories about ourselves to ourselves.

We also want to connect with people close to us. If we've both played the same game, we can discuss the challenges and possible solutions, the characters and story, and how we feel about the identities and values in the game. Suppose we both play September 12th and discuss it. Perhaps we agree the issues in "the war on terror" are more complex than we once believed. Our discussion of the game can help us find or develop shared understandings and beliefs. Some video games allow people to play together at the same time, in cooperative or competitive ways. These games create even richer possibilities for discussion and relating both during and after playing. In some multiplayer video games, the solo gameplay can grow repetitive and tedious. But these games remain appealing and satisfying because of the social interaction and especially the interaction within teams or groups (e.g., World of Warcraft, EVE Online, Fallen Earth). As McGonigal argues in Reality is Broken (2011), immersion in a multiplayer game can inspire players to see how when we work together we can achieve goals and make the real world a better place (p. 13-14).

That brings us to the third way we want to connect: as a society. As a society, we continually define and redefine our values, including our principles and policies on everything from human equity to economic prosperity to environmental conservation. Some of this discussion is formal and/or abstract, via editorials, articles, books, televised interviews and debates, campaign speeches, sermons, and so on. But much of this discussion is informal and concrete via media that's ostensibly recreational. These latter media include enduring literature like Shakespeare as well as popular media like television comedies, action movies, and hit music. Laurel (2001) deftly explains how pop media gives us a context to define and redefine ourselves and our beliefs:

When artists and philosophers talk only amongst themselves, they ignore the potential of popular culture to become a variety of dialogues with and between everyday people. Its discourse may be productive of desire and pleasure, but popular culture is also a language in which people discuss politics, religion, ethics, and action. (p. 11)

Moats (in Werts, 2008b) expresses a similar idea regarding art: "It stimulates us to think, even for just a few minutes, in a new way...." The stories in video games can preserve, unpack, transmit, and challenge perspectives and values. At their best, video games can influence players' beliefs and values in nuanced ways. Once we've played September 12th we may respond differently to a news report of the accidental killing of civilians in a war zone. Once we've played Beyond Good \& Evil we may respond differently in a discussion about how governments sometimes pressure reporters to reveal their sources. 
In other media, artists have both reflected and influenced our society's self-awareness and decisions.

Consider how Bob Dylan and other songwriters echoed and inspired activists in the 1960s. Consider how Michael Moore and other directors use movies to educate and agitate. Consider how Jon Stewart uses The Daily Show - ostensibly, it's a comedy TV show - to editorialize about current issues and criticize politicians and other journalists. There aren't comparable examples among video games yet, partly because most commercial video games are designed only for recreation. Few video games deliberately engage with important issues like September 12th and Beyond Good \& Evil. But video games have as much or more power to influence players, and many designers are already creating games that do more than entertain.

\section{How Librarians Can Respond}

We have discussed the role of libraries in changing times and explained many of the possible benefits of games. We'll now offer some advice and examples of how librarians can integrate video games into library collections and programming, as well as how librarians can use video games as a gateway to introduce patrons to other materials.

We'll describe many specific games as a starting place. Other similar games might work just as well, and as time passes, newer games will work even better. Librarians may want to recruit the expertise of some gamers, share these guidelines, and get advice on what's available and timely.

\section{Selecting Games: Guidance}

If librarians decide to integrate games into library collections, guidance will probably be their first concern. There is an endless variety of new games and kinds of games. Here are some criteria for deciding which games to integrate.

When adding games to a library's collection, many factors need to be considered. Will the games be part of the general collection, a review/curriculum collection, or only available for library staff to use for programming? If they are part of the general collection, will the systems circulate as well as the games? Will the library create a gaming lab? Will the games be mostly single-player, multi-player, or both? Will the library buy games for multiple consoles (e.g., Nintendo Wii, Microsoft Xbox 360), or just one? From where will all of these games and systems be purchased?

Once these questions have been answered, the first step is deciding on which games to purchase. Advice and assistance from experienced gamers can be very helpful. If librarians feel that the games will be used mostly for library programming or group play, they should select multiplayer games. Co-Optimus.com is a great resource for selecting multiplayer games. Each game is given a quality rating, as well feature tags, such as the number of players and type(s) of cooperative play allowed. ("Couch Co-Op" games are usually best, since they allow 1-4 people to play on the same screen at the same time.) Library publications such as Library Journal also occasionally publish video game reviews and best video game lists. Librarians should become familiar with the different types of video games that are available, and add a sampling of both popular and critically-praised games from each gaming genre. These genres include shooters (e.g., Halo series), action-adventure (e.g., Uncharted series), racing (e.g., Mario Kart series), role-playing games (e.g., Final Fantasy series), party (e.g., Mario Party series), and more.

Librarians should consider age appropriateness. Games have content/age ratings similar to movies. The Entertainment Software Ratings Board (ESRB) ratings are an excellent way to initially decide whether a game is appropriate for younger players. The main ratings are E: Everyone, T: Teen, and M: Mature (17+). The rating for a game appears on the cover, with additional content descriptors on the back. Libraries can help patrons learn about the ESRB ratings by displaying posters near games, providing handouts, and including information and links on the library webpage. The ESRB website provides information about the 
content of the games and resources for parents (e.g., how to set parental controls on an Xbox, practicing online safety, etc.). Libraries may want to start with only E or T-rated games, and restrict young patrons' access to $\mathrm{T}$ games (just as they might do with PG-13 movies).

If a library includes M-rated games in their collection, then the content of these games may be confusing to some patrons. A patron may believe that video games are "just for kids", in which case the content of an Mrated game seems pernicious. Also, some patrons may believe that all video games are crude or shallow. However, games aren't just for kids and games are growing in sophistication. Libraries can provide inviting opportunities to learn about these trends, including the possible editorial or literary value of games aimed at older audiences (e.g., September 12th). This can be as simple as setting up displays of games, pointing patrons to websites about video games, or creating "suggested playlists" of quality, provocative games. Some useful websites to help patrons and librarians navigate the flood of video games are Game Rankings.com, IGN.com, Co-Optimus.com, and GameSpot.com.

Librarians should consider which game systems they want to support. If the system is selling well, many patrons will own the system and many games will be published for the system. For example, over the past few years, the Nintendo Wii sold very well. However, before the Wii was released, some experts and game designers were skeptical that it would be successful. Librarians should probably wait at least 8-12 months after a new system is released before deciding whether to support it.

Some libraries should consider two special populations of patrons: educators and game scholars. This is especially true for education libraries. The first population, educators, may be interested in the potential of games to motivate and educate students. There is a growing body of games and research to support teaching using games. Libraries may want to create a special collection of some of these "serious games", for educators to explore and experiment with. Some starting places for advice and ideas include educationarcade.org, seriousgames.msu.edu/companies.php, and www.gamasutra.com/topic/serious. The last site, Gamasutra, is a games industry organization and can connect librarians with game professionals in their area (e.g., as guest speakers). Some books offer both theories and practical advice for instructors and education students who want to integrate video games into the classroom, including Video Games and Learning: Teaching Participatory Culture in the Digital Age and The Work of Play: Meaning-Making in Videogames. Some widely-respected publishers of educational games are Firaxis, Muzzy Lane, and Leapfrog.

The second special population is game scholars. As games grow into an industry and art form, increasingly, creators, critics, and scientists study and debate issues such as innovation, artistry, and the positive and negative effects of games. If librarians want to integrate games that scholars are discussing, they can look to

relevant blogs, articles, and books (cf. the books by Gee that we cite in this article). Best-selling games often generate a lot of analysis and discussion, but so do less popular but critically-acclaimed games like Beyond Good \& Evil. Librarians may want to integrate both kinds of games to meet the interests of professional and amateur games scholars.

\section{Adding Games: Access}

Librarians can provide access by adding a wide variety of video games to their collections, making them easy to locate in the library catalog and the building, and making them easy to check out. Libraries can also consider checking out game systems. Patrons who are hesitant or unable to spend money on gaming could still discover and enjoy games.

In the building, games can be displayed prominently or can join books in a new acquisitions display. A game can be set up as a kiosk, inviting patrons to pick up controllers and play (Figure 6). Another way to make 
patrons aware of the availability of games in libraries is through advertising and outreach. Social media such as Facebook, blogs, and Twitter are a great way to share news with patrons. In an academic setting, student groups and residence life staff can be notified of how they may check out materials for their own programming, and professors can be notified of possible ways to integrate gaming into their curriculum. For example, many online games like World of Warcraft, RuneScape, and Second Life draw players from other countries. Students in a foreign language course could play and converse in the language they're studying.

Figure 6. A kiosk with a playable Wii game

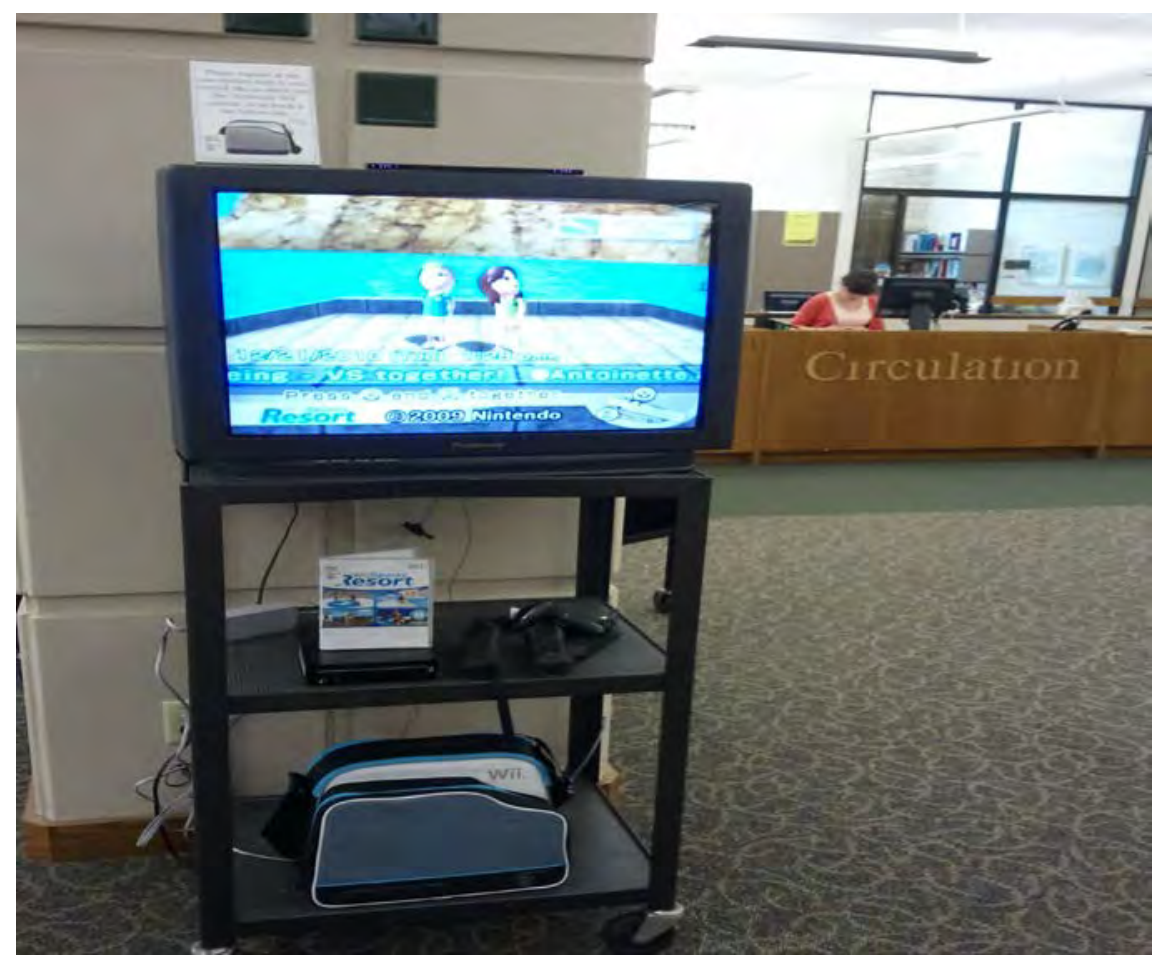

Video games can be purchased from library suppliers (e.g., DEMCO), a department store (e.g., Target), or a store specializing in video games (e.g., GameStop). Specialized stores sell both new and used games, in their brick-and-mortar stores and online. Purchasing used games is a good way to obtain games that may be older and more difficult to find. It can also add up to substantial savings, especially when combined with a savings program such as GameStop's PowerUp Rewards program. This program includes a discount on used games. Other stores offer similar customer-loyalty programs. Local used-game and retro-gaming stores can be a good way to obtain older systems and games (e.g., to replace systems that wear out).

If librarians decide to make video games part of the collection, they must decide on how to catalog them, a loan period, where they will be shelved, and how to address the issue of possible theft. In recent years, cataloging standards have emerged for Library of Congress and Dewey for cataloging video games and related equipment. A library may want to make a loan period that is similar to other media, such as movies, to avoid confusion among patrons and circulation staff. When shelving video games, security should be considered. One solution is to place all games in plastic cases that must be unlocked by circulation staff upon checkout. (These cases were developed for retail stores and are easily purchased.) Another, lower-cost solution is to place empty "dummy cases" on the shelves, and keep the cases containing the games at the circulation desk. If librarians decide to circulate systems, controllers, and other accessories, it is important to make sure they are transported in appropriate cases (to protect against weather and accidental damage). A 
variety of carrying cases and bags have been made specifically for each system and accessories. They can be found at many stores that sell video games, such as Toys R' Us, as well as Amazon.com.

Many games have a limited shelf life. Within a few years after their publication, a specific game may decline in popularity with most players. This is especially true when a new game system comes out; players may no longer buy or keep the old system. This is similar to how DVD slowly replaced VHS as a video format, requiring libraries to sunset the older format. Happily, many game systems support some backwards compatibility, but only up a point. For example, the first version of the PlayStation 3 supported PlayStation 2 games, but newer versions of the PlayStation 3 abandoned this backwards compatibility. For any game system, librarians probably want to integrate both the system and its games into their collections to ensure that the games can be played for a long time.

Some great games have lasting appeal: they will continue to appeal to players for years. Also, there is a thriving "retro gaming" culture in which players enjoy old or very old games. (In the context of video games, "retro" may be 15-20 years ago.) However, the majority of patrons will probably prefer newer games.

A game may have strict digital rights management (DRM) restrictions that prevent the owner from playing the game on more than one specific game system (e.g., on more than one specific PlayStation 3). A game with this kind of DRM couldn't be checked out, but patrons could still enjoy playing it at the library on a non-circulating game system. An increasing number of games are published via direct download (instead of a disc sold at retail), and most of these games have strict DRM.

Academic librarians who want to support educators and game scholars may want to create a special review collection. This collection should contain a sampling of games of different genres, as mentioned above. As part of the review collection, it may be a good idea to not only allow students to check out the resources, but also to have one or two stations set up so they can sample the games at their convenience. Librarians can promote awareness of the collection through the programming they offer to academic areas (e.g., education, computer science).

\section{Inviting Player: Motivation}

Motivation can be increased by making patrons aware of this availability in different ways. For instance, libraries can add gaming to their existing programming and interest groups. An obvious match may be programming or groups for children or young adults, but the potential audience may be broader. A senior citizens group can have fun with Wii Sports Resort, with its gameplay like bowling and canoeing, when mobility issues may otherwise prevent them from enjoying these recreations. Many Wii games include a random succession of active, silly games, like those in WarioWare: Smooth Moves Wii. These can be used for a group learning English as a second language if players are asked to describe the actions in each mini game. A teen group could host a Mario Kart or Super Smash Bros. Brawl tournament, a parent-child group could enjoy Sesame Street: Once Upon a Monster, and a LEGO group could enjoy LEGO Star Wars. Libraries can organize player groups in massively multiplayer online games (MMOs) like World of Warcraft. (Such groups are called "guilds" or "clans.") Some MMO groups already try to meet face-to-face so libraries could be a great venue for fostering the interpersonal connections that deepen and extend the gaming experience.

As with motivation in any medium, librarians first need to feel motivation about games themselves. Library staff may benefit from special training to provide motivation and guidance on games and gaming. This could include a training session or just creating a webpage of useful links. A staff training session can be a particularly useful experience since it provides a place to learn about gaming resources and to discuss some of the misconceptions surrounding video games. When librarians play games with each other and with 
patrons, they may get a taste of why so many people like to play (Figure 7). Librarians can also practice the kinds of formal and informal conversations that help others develop advanced literacies like critical literacy. Then when librarians run programs or facilitate interest groups, they can help players process on their experiences and analyze games more fully.

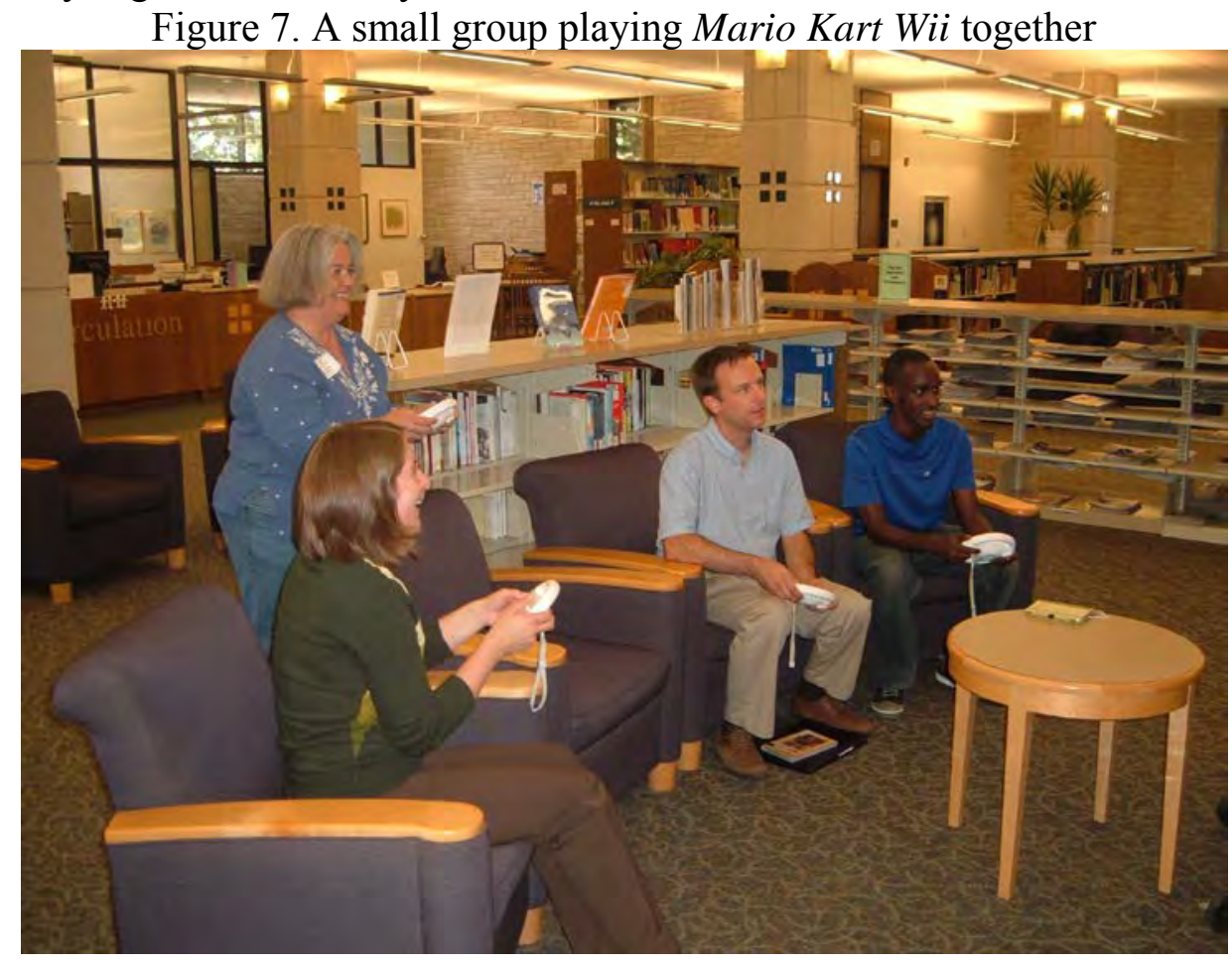

Motivation not only refers to helping patrons make responsible decisions in regard to video games, but also in suggesting games that patrons may not have heard about in popular media, or may have overlooked in a retail setting. For example, Beyond Good \& Evil didn't sell well. If it had been showcased in libraries, its provocative message may have reached more people. Fortunately, it's gained a reputation as a cult classic, which helped fuel an updated version and work on a sequel. Perhaps this time more libraries will have the opportunity to help more people discover this kind of game. More broadly, the video games industry is trying to diversify to include more independent and experimental games, especially via download (e.g., online app stores). Like independent movies, independent games sometimes struggle to reach a large audience. Libraries can help.

Academic librarians may be interested in holding information sessions or an open house for instructors and education students to familiarize them with different resources and methods of integrating video games. These programs will not only introduce them to resources, but could also be a great way for instructors and students to share creative ideas. Another motivation strategy is creating a web page or LibGuide with links to browser-based games and web-based resources. This can help steer instructors toward web-based serious games, as well as sites that allow players to create their own games. For example, see:

http:/guides.lib.lawrence.edu/games

Libraries can also offer access, motivation, and guidance to games that promote physical activity. The Nintendo Wii is particularly impressive in encouraging and rewarding more physical play, including games designed to be played standing up with large body movements. Other games that encourage more physical play are the Guitar Hero, Rock Band, and Dance Dance Revolution series. The Xbox 360 Kinect and PlayStation 3 Move game systems also promote physicality. The next generation of gaming systems will probably include even more possible physicality. In addition to connecting patrons with more active games, 
libraries can offer general guidance on balancing sedentary media with an active lifestyle, including taking breaks and avoiding repetitive stress injuries.

\section{More Connections}

Libraries can do more to help patrons connect more with each other and with society. We've already described many possible programs and interest groups. Here are more strategies.

Based on patrons' interest in games, librarians can guide them towards other promising materials. Librarians can intermingle the eye-catching boxes of current hot games with books of the same genre or content ("If you like __, you may like this!"). A patron who has played September 12th could be guided towards relevant reading on the issues of religious extremism, totalitarian governments, intervention in the Middle East, terrorism, friendly fire, collateral damage, and alternative strategies to missile strikes (with their pros and cons). A patron who enjoys playing the Halo game series may be interested in materials related to military experimentation, science fiction about alien invasions, or the Halo series of novels, which provides backstory for the games and completely new stories and characters set in the same world. Patrons can also be guided toward game-related magazines, such as EGM or Game Informer, gaming strategy guides, and gaming-related non-fiction. Non-fiction titles can cover a range of topics, including growing up gaming (e.g., Dungeons \& Dreamers), profiles of game designers (e.g., Shigeru Miyamoto: Nintendo Game Designer), and working in the gaming industry (e.g., Paid to Play). Older teens and college students may even be interested in the growing field of research surrounding video games, including gaming culture, game music, games as art, etc. Librarians can also ask patrons about which types of games they like, and use that knowledge to recommend books that fall within that genre.

Like Halo, other games have inspired fiction, including Mass Effect, Resident Evil, Sonic the Hedgehog, Gears of War, Starcraft, .hack, Doom, and City of Heroes (Invasion). Conversely, some games are inspired by fiction. Tom Clancy's novels have inspired a variety of games. American McGee's Alice and Alice: The Madness Returns are inspired by Lewis Carroll's Alice stories. Orson Scott Card's Empire inspired Shadow Complex. And many comic books and graphic novels have inspired video games, including Batman: Arkham Asylum. If librarians can use video games to make connections with patrons, they may promote a love of reading, via both traditional and non-traditional texts.

Pop media in general inspire a great deal of fan fiction, and video games are no different. Some players use the setting and characters to tell stories beyond the scope of the game. Some fledgling authors may find it more motivating and easier to use existing settings and characters. Some authors may enjoy exploring "what if" scenarios, like, "What if Harry Potter was a girl?" or "Who would win if spaceships from Star Wars and Star Trek fought?" Librarians and teachers can use this connection to encourage adolescents to write creatively, and to discover a love of reading. Library contests and events can even be planned around fan fiction, or librarians could even offer to make fan fiction available on the library's website.

Video games also inspire players to create other secondary media. These media can be very in depth and include walkthroughs describing how to play a game from start to finish, lists of Frequently Asked Questions (FAQs) with answer that describe key ideas and critical strategies, player-written reviews, and conversations on discussion forums and fan websites. Walkthroughs and FAQs allow players to demonstrate mastery of a game, while providing a useful resource to other players who may be struggling to succeed in the game. Some video games encourage or depend on user-created content. Players with advanced programming skills can create new levels or other new in-game content. The "mods" can include tweaking small parts of the game, or "total conversions", in which players essentially create new narrative structures and/or gameplay using the pieces of an existing game. For example, in the PC game World of Warcraft, players create and share "mods" that assist other players with game play. Entire player-run websites exist for the purpose of 
sharing user created content. Some focus on a single game (e.g., WoWWiki.com), while others contain content for thousands of games (e.g., GameFAQS.com). Librarians can encourage patrons to use as well as create user-created content by providing links on a gaming section of a website, or by forming an interest group that centers on a certain game, such as World of Warcraft.

Programming or groups about gaming don't always need to include playing games. Libraries can have "meetthe-author" talks from game designers, authors, journalists, researchers, and more. Libraries can show movies based on video games, such as Final Fantasy VII: Advent Children or Prince of Persia: The Sands of Time, or gaming documentaries, such as Second Skin or The King of Kong, and then facilitate post-viewing discussions.

There are many possible ways to bring games, gamers, and gaming culture into libraries. We've provided some promising strategies and we encourage librarians to imagine more.

\section{Conclusion}

Video games are an astonishing medium with distinctive features, including visual communication, interactivity, and simulation. Games like September 12th and Beyond Good \& Evil can communicate powerful ideas using immersion, challenge, and connection. We hope to see more creative and compelling games in the near future.

Like any medium, video games will grow in sophistication as more players become a more literate audience, and as some of those players later become game designers. We hope more libraries and librarians find a place for video games so that more people can discover and enjoy them. Librarians are part of our collective conversation around issues like freedom of expression and meaningful literature. Librarians can join the conversation around video games, helping to shape the art and culture of video games with the kinds of showcases and activities we've described. When librarians bring games into their libraries, they may also be reaching out to people who may not normally spend time in libraries.

Now is a good time to explore video games. We live with a flood of new gadgets and wizardry. Libraries can help patrons survive and thrive in this flood. More people--especially young people--will benefit if they have more access to good games, more motivation to play them, and more guidance in critical literacy and reflection. The video games industry is driven by for-profit retail sales. Libraries can provide another context for finding, playing, and appreciating good games.

\section{Works Cited}

Aarseth, E. J. (1997). Cybertext. Baltimore, MD: The Johns Hopkins University Press.

Aldrich, C. (2004). Simulations and the Future of Learning. San Francisco, CA: Pfeiffer.

American Library Association. (n.d.). Censorship \& First Amendment Issues. Retrieved November 14, 2012, from http://www.ala.org/advocacy/intfreedom/censorshipfirstamendmentissues

Barthes, R. (1968/1977). The Death of the Author. In S. H. (Trans.) (Ed.), Image Music Text (pp. 142-148). New York: Hill and Wang.

Barthes, R. (1971/1977). From Work to Text. In S. H. (Trans.) (Ed.), Image Music Text (pp. 155-164). New York: Hill and Wang.

Bertz, M. (2011, November). Ubi Uncensored. Game Informer, 40-49.

Brown v. EMA, 564 U.S. (2011). Slip Opinion. Retrieved August 31, 2011, from http://www.supremecourt.gov/opinions/10pdf/08-1448.pdf

Buchanan, K. (2006). Beyond attention-getters: Designing for deeper engagement. (Unpublished doctoral dissertation). Michigan State University, East Lansing, Michigan. 
Buchanan, K., \& Cook, P. (Winter 2011-2012). Playing the believing game with Dr. Seuss and reluctant learners. The Journal of the Assembly for Expanded Perspectives on Learning, 17: 31-41.

Csikszentmihalyi, M. (1990). Flow: The Psychology of Optimal Experience. New York: HarperPerennial. Galarneau, L. (2005). Authentic Learning Experiences Through Play: Games, Simulations and the Construction of Knowledge. Paper presented at the DiGRA 2005 Conference, Vancouver, Canda.

Gee, J. P. (2003). What Video Games Have to Teach Us About Learning and Literacy. New York: Palgrave Macmillan.

Gee, J. P. (2005). Why Video Games are Good for Your Soul. Altona, Victoria: Common Ground.

Honebein, P. C. (1996). Seven Goals for the Design of Constructivist Learning Environments. In B. G. Wilson (Ed.), Constructivist Learning Environments: Case Studies in Instructional Design (pp. 1124). Edgewood Cliffs: Educational Technology Publications.

Karas, D. (2011). Public libraries fight to stay relevant in digital age. The Christian Science Monitor. Retrieved November 14, 2012, from http://www.csmonitor.com/layout/set/print/USA/Society/2011/0627/Public-libraries-fight-to-stayrelevant-in-digital-age

Johnson, S. (2006). Everything Bad Is Good For You: How Today's Popular Culture Is Actually Making Us Smarter. New York: Berkley Publishing Group.

Laurel, B. (2001). Utopian Entrepreneur. Cambridge, MA: MIT Press.

McGonigal, J. (2011). Reality is Broken. London: Penguin Press.

Newsgaming.com. (2003). September 12th. (Video game via web browser). Montevideo, Uruguay.

Papert, S. (2002). Hard Fun. Bangor State News. Retrieved October 12, 2011, from http://www.papert.org/articles/HardFun.html

Rideout, V., Roberts, D. F., \& Foehr, U. G. (2005). Generation M: Media in the Lives of 8-18 Year-olds. Menlo Park, CA: The Henry J. Kaiser Family Foundation.

Rodriguez, H. (2006). The Playful and the Serious: An approximation to Huizinga's Homo Ludens. Game Studies, 6(1).

Salen, K., \& Zimmerman, E. (2004). Rules of Play: Game Design Fundamentals. Cambridge: The MIT Press.

Shaffer, D. W. (2006). How Computer Games Help Children Learn. New York: Palgrave Macmillan.

Siu-Runyan, Y. (2011). Public and School Libraries in Decline: When We Need Them. The Council Chronicle (NCTE), 21(1), 28-29.

Squire, K. (2006). From Content to Context: Videogames as Designed Experiences. Educational Researcher, 35(19), 19-29.

Ubisoft. (2003). Beyond Good \& Evil. (Video game via Nintendo GameCube). Paris, France.

Werts, C. E. (2008a). Information Literacy in Real Life and in Second Life. Education Libraries, 31(2), 6-11.

Werts, C. E. (2008b). Interview with Tamara Moats, Speaker on Visual Thinking and Use of Art Data.

Education Libraries, 31(2), 39-42.

September 12th images (Figures 1, 2, and 3) were taken directly from the game.

Beyond Good \& Evil cover image (Figure 4) was retrieved September 9, 2011 from

http://image.com.com/gamespot/images/bigboxshots/6/561646_front.jpg

Beyond Good \& Evil gameplay image (Figure 5) was retrieved September 9, 2011 from

http://tleaves.com/weblog/images/articles/beyond2-dont-steal-bandwidth.jpg

\section{Kym Buchanan}

University of Wisconsin Stevens Point

School of Education (446 CPS)

2100 Main Street

Stevens Point, WI 54481

kbuchana@uwsp.edu

\section{Angela M. Vanden Elzen}

Seeley G. Mudd Library

Lawrence University

113 S. Lawe St.

Appleton, WI 54911

angela.vandenelzen@1awrence.edu 